
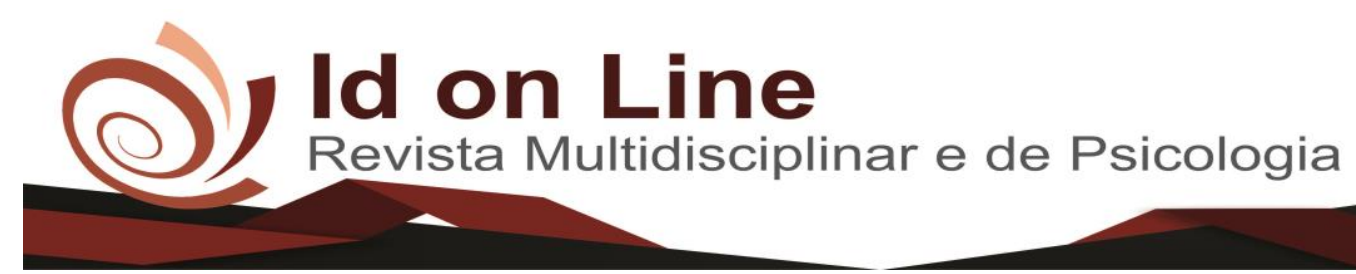

Artigo de Revisão

\title{
Doença de Alzheimer nas Mulheres: Prejuízos Pessoais e Luto Familiar
}

\author{
Melina Raabi Santos Fernandes ${ }^{1}$; Maria do Socorro Teles de Melo²; Thercia Lucena Grangeiro Maranhão ${ }^{3}$; \\ Fernanda Tesla Pereira Sampaio ${ }^{4}$; Hermes Melo Teixeira Batista ${ }^{5}$
}

\begin{abstract}
Resumo: O artigo tem como tema: mulheres com doença de Alzheimer,prejuízos pessoais e luto familiar. O objetivo principal é verificar os prejuízos que a doença de Alzheimer traz para o cotidiano de uma mulher portadora e seus familiares;. A escolha do tema deu-se a partir do interesse em conhecer e compreender a realidade apresentada às mulheres acometidas pela doença de Alzheimer e seus familiares. A pesquisa é uma Revisão Literária, método de pesquisa que busca, analisar e descrever sobre determinado assunto em literaturas, englobando matérias escritos relevantes diante do tema. A doença de Alzheimer é uma demência degenerativa que acomete principalmente mulheres mais velhas, que ocasiona grandes mudanças para essa mulher portadora e seus familiares; dentre os vários sintomas manifestos nessa paciente, o mais comum são as falhas de memórias, o que traz grandes prejuízos a paciente, família e os cuidadores.
\end{abstract}

Palavras-chave: Doença de Alzheimer. Limitações. Alterações. luto familiar. Perda de identidade.

\section{Alzheimer's Disease in Women: Personal Injury and Family Mourning}

\begin{abstract}
The article has as its theme: women with Alzheimer's disease, personal injury and family mourning. The main objective is to verify the damages that Alzheimer's disease brings to the daily life of a woman carrier and her relatives. The choice of topic was based on the interest in knowing and understanding the reality presented to the women affected by Alzheimer's disease and their relatives. The research is a Literary Review, research method that seeks, analyze and describe a certain subject in literatures, encompassing relevant written matters before the theme. Alzheimer's disease is a degenerative dementia that affects mainly older women, which causes great changes for this female carrier and her relatives; Among the various symptoms manifested in this patient, the most common are memory failures, which causes great harm to the patient, family and caregivers.
\end{abstract}

Keywords: Alzheimer's disease; limitations; changes; Family mourning; Loss of identity.

\footnotetext{
${ }^{1}$ Graduanda em Psicologia pelo Centro Universitário Doutor Leão Sampaio; E-mail: raabimelina@gmail.com.

${ }^{2}$ Graduanda em Psicologia pela Faculdade Pernambucana de Saúde - FPS ;E-mail: mariasocorro9@yahoo.com.br;

${ }^{3}$ Psicóloga. Especialista em Gestão do Trabalho e da Educação na Saúde pela Escola de Saúde Pública do Estado do Ceará .Pós- Graduanda da Mestrado em Ciências da Saúde pela Faculdade de Medicina do ABC-FMABC, do curso de. Professora do Centro Universitário Dr. Leão Sampaio;Membro do Comitê de Ética em Pesquisa da UNILEÃO. Coordenadora do Núcleo Cariri da ABRH-CE. E-mail: thercia@leaosampaio.edu.br;

${ }^{4}$ Psicóloga pelo Centro Universitário Doutor Leão Sampaio. Contato: ftesla@ hotmail.com;

${ }^{5}$ Médico pela Universidade Federal do Ceará - UFC. Médico do Hospital Regional do Cariri. Mestrado e Doutorando pela Faculdade de Medicina do ABC. Santo André-SP. Contato: hermesmelo@oi.com.br
} 


\section{Introdução}

O mal de Alzheimer se tornou prevalente com o aumento da expectativa de vida e afeta, segundo dados do Ministério da Saúde, cerca de 1,2 milhões de pessoas no Brasil, homens e mulheres, com mais prevalência nas mulheres, e a cada ano são registrados 100 mil novos casos, o que significa aproximadamente duzentas e oitenta pessoas por dia e metade dessa população não recebe tratamento adequado (ABRAZ, 2012).

Segundo a Classificação Internacional das Doenças (CID 10) a doença de Alzheimer é uma doença degenerativa cerebral primária, a sua causa e origem ainda são desconhecidas. Essa demência geralmente se manifesta a partir dos 60 anos, podendo em casos raros acontecer antes dessa idade. A perda da memória de manifesta no início da doença, que pode ser inicialmente leve, moderada ou grave. Ocasionalmente, a doença evolui lentamente, quando o inicio é lento ou moderado, não há estabilidade inicial por ser uma sindrome de natureza neurodegenativa e progressiva. Com o tempo começam a desenvolver e manifestar outros sintomas, como os transtornos neurocognitivos leves e maiores, alterações de personalidade e dificuldades neurológicas.

O Departamento Científico de Neurologia Cognitiva e do Envelhecimento da Academia Brasileira de Neurologia recomenda atualmente para o diagnóstico de doença de Alzheimer no Brasil a presença de pelo menos dois sintomas cognitivos ou comportamentais, que afetam no mínimo dois dos seguintes domínios: memória, funções executivas, habilidades visuais e espaciais, linguagem e personalidade ou comportamento.

Para as doenças neurodegenerativas ainda não há previsão de cura em curto prazo, porém para o diagnostico e tratamentos existem avanços cientificos que possibilitam retardar o avanço da doença proporcionando melhor qualidade de vida aos pacientes. Entre os medicamentos aprovados pela Alzheimer's Association,2010 está a cloridrato de memantina (namenda - é o nome comercial da droga nos Estados Unidos, não sei se seria legal citar) que reduz a degeneração cerebral, com poucos efeitos colaterais. Como tambémo donepezil, que é inibidor da colinesterase, para reduzir e estabelizar o progresso da demência leve ou moderada (PAPILA e FELMDMAN,2013).

Para a Organização Mundial da Saúde (OMS,2012) e a Associação Internacional de Doença de Alzheimer (AID) a demência é uma prioridade de saúde pública, as mulheres idosas apresentam maior probabilidade de desenvolvê-la, levando a um declínio funcional 
mais considerável. A Pesquisa Nacional por Amostra de Domicílio (PNAD) de 1998 e 2003 concluiu que as mulheres idosas procuram atendimento médico em maior proporção que os homens, independente de classes sociais, talvez essa seja uma das causas da prevalência mais no sexo feminino uma vez que nos homens o diagnóstico é mais tardio.. A demência é uma doença com grande prevalência em idosos, acometendo em maior proporção mulheres, esse problema por sua vez é devastador, tanto para o paciente quanto para a sua família, já que incapacita o paciente nessa fase da vida.

A doença de Alzheimer é a demência mais comum, que traz mudanças anormais no tecido cerebral. Inicialmente surgem alterações de memória e apatia, geralmente passam despercebidos pela família; posteriormente vão surgindo outros sintomas como déficits da função cognitiva, dificuldades de exercer atividades motoras e atividades rotineiras.

O estudo basea-se na hipotese dos problemas incapacitante que o mal de Alzheimer traz para os seus portadores, o que proporciona grandes prejuízos para a rotina da paciente. Inicialmente, a perda de memória pode ser leve com o prognóstico de chegar possivelmente a fase mais grave. $\mathrm{O}$ esquecimento de palavras e de acontecimentos recentes geralmente devem ser vistos como um alerta para se buscar ajuda médica. Com o avanço da doença há significativa degeneração de neurônios no núcleo basal, levando a redução substancial na inervação colinérgica cortical começando a surgirem os sintomas externos, a perda da memória, incapacidade de não conduzir seus atos de rotina, incapacidade de efetuar movimentos voluntários e propositados, dificuldade ou perda da capacidade de falar, alteração no comportamento, perda de peso e mudança de humor ( KAPLAN e SADOCK, 2017)

Diante do exposto acima, surge o seguinte questionamento: quais os prejuízos que o Alzheimer apresenta para as mulheres acometidas pela doença e seus familiares? A fim de responder tal questionamento, este artigo tem como objetivo principal verificar os prejuízos que a doença de Alzheimer traz para o cotidiano de uma mulher portadora dessa doença e também para seus familiares. Pretende-se também, identificar as limitações causadas pela doença de Alzheimer; e ainda analisar o sofrimento e dificuldades enfrentados com a perda da identidade durante o processo de adoecimento, posteriormente, compreender as angútias e o luto vivenciado pelos familiares.

A escolha do tema justifica-se a partir do interesse em conhecer e compreender a realidade apresentada às mulheres acometidas pela doença de Alzheimer e seus familiares, já que se trata de uma temática que nas últimas décadas cada vez mais pessoas têm passado pela 
experiência de conviver com o sofrimento causado a sujeitos e familiares que lidam com esse triste fato.

Pode-se então buscar subsídio para identificar se a Doença de Alzheimer tem relação tanto com os fatores sócio-ambientais quanto com fatores genéticos, conforme revelado em pesquisas recentes. Não há ainda consenso sobre o diagnóstico e o tratamento da doença, embora existam avanços cientificos sobre o assunto, o que facilita a prevenção e a possível cura. Como essa é uma doença que tem forte prevalência em mulheres da terceira idade, é de grande valia encontrar através de pesquisa a confirmação do diagnóstico e tratamento eficaz, pela grande importância para a sociedade.

\section{A Doença de Alzheimer}

A doença de Alzheimer (DA) é a demência mais frequênte na terceira idade. É de caráter degenerativo do tecido cerebral, com deficit progressivo das funções cognitivas, de instalação e evolução em três estágios principais: inicial ou leve, intermediária ou moderada e avançada ou grave. O primeiro sintoma é a dificuldade de memória recente e episódica o que geralmente leva o paciente a procurar ajuda médica. A memória é afetada paulatinamente e traz prejuízos a função ativa e a capacidade de desenvolvimento cognitivo, após um període de tempo curto, dois ou três anos, começam a surgir outros sintomas de prejuízos nos afazeres e diminuição da capacidade de exercer atividades motoras, com o avanço dos sintomas aparecem alterações do ciclo sono-vigilia, acompanhados de irritação e hiperatividade, posteriormente a pessoa torna-se dependente, geralmente precisando de um acompanhante que execute suas atividades rotineiras.

Quando o paciente preenche os crítérios do DSM-V, com problemas neurológicos característicos das demências, exemplo atrofia cortical e alterações hipocampais, apresentados em exames de neuroimagens, o diagnóstico pode ser clínico e neuropatológico. O diagnóstico definitivo requer o diagnóstico clínico e a detecção pos morten, este com a observação das alterações histopatológicas do cérebro, como emaranhados neurofibrilares no hipocampo e neocortex. (PESKING e RASKIND,1999).( M0rais...)

Segundo Sadock J. e Sadock A. (2007), Alois alzheimer foi o primeiro médico que identificou a doença de Alzheimer no ano de 1901. Sua primeira publicação aconteceu em 
1906, após a morte da primeira paciente que foi acompanhada por ele, denominada Auguste D. que tinha cinquenta anos e foi diagnosticada com a demência de Alzheimer. A partir dessa publicação a demência recebeu a denominação de "doença de Alzheimer". Nos cinco anos seguintes foram registrados na literatura médica onze casos semelhantes, que já recebia o termo Alzheimer.

Atualmente estão sendo feitas várias pesquisas para encontrar as causas do Alzheimer, principalmente nos países desenvolvidos como Estados Unidos. Já se sabe que há uma maior prevalência entre mulheres mais velhas, ou seja, essa demência varia em relação ao sexo e a idade. As pesquisas também mostram os fatores de risco estudados, que podem ser: fatores hereditários, traumatismo craniano, síndrome de Down, fatores genéticos como a identificação da variante $\varepsilon 4$ do gene apolipoproteina $\mathrm{E}$ (apoE) como o fator de risco mais comum para a DA de início tardio, doença de Parkinson, escolaridade baixa, depressão e alguns outros. Lembrando que a simples presença desses fatores não são necessários e nem preponderantes para que se desenvolva a DA(SCAZUFCA,2006). Estudos que exploram a interação gene-ambiente e outros fatores podem explicar parte da variação geográfica da doença."(SENA,2006).

Litvoc e Brito (2004), afirmam que as mulheres experimentam o processo de envelhecimento com o desgosto, sofrimento e vergonha, portanto o envelhecer traz profundo sofrimento às mulheres. O sofrimento dessas mulheres no inicio da doença é angustiante, porque começam a compreender sua real situação. Nas manifestações iniciais estão o esquecimento de eventos recentes e a apatia, por ser uma doença neurodegenetariva, a evolução da doença é de caráter progressivo. Surge então déficts de atenção, de memória, de função cognitiva, alterações de concentração, mudanças de personalidade, incapacidade de executar atividades diárias e motoras, alterações neuropsicomotoras, alterações de comportamento e como consequencia perda do "freio social". Por todos esses prejuízos e alterações, os portadores da DA tornam-se, com o tempo, totalmente dependentes do cuidador externo e de familiares.

\section{O Envelhecimento e seus compromentimentos}


Os conceitos de terceira idade, velhice e envelhecimento, encontram-se em expansão. O envelhecimento populacional tem sido objeto de pesquisa de muitos estudiosos no assunto, com o aumento da população idosa tem havido sérios problemas no contexto da sociedade brasileira. Os idosos são, conforme dados do Instituto Brasileiro de Geografia e Estatistica (IBGE) o segmento populacional que mais cresce no Brasil. A Organização Mundial de Saúde (OMS) prevê que em 2025 existirão em todo o mundo, 1,2 bilhões de pessoas com mais de 60 anos. No Brasil a projeção é de 34 milhões de pessoas idosas para o mesmo ano, o que deixará o país na $6^{a}$ posição como o mais envelhecido do mundo (OMS, 2001). O aumento dessa população gera uma série de implicações econômicas, sociais e de saúde com maior quantidade de gastos com medicamentos, tratamentos e aumento dos transtornos mentais e doenças crônicas ( Barreto, Carreira \& Marcon, 2015).

$\mathrm{O}$ envelhecimento envolve alterações estruturais e funcionais significantes. Segundo Ramos (2003), a funcionalidade é um padrão de saúde dos idosos que têm um perfil de independência a ser atingido, não está relacionado a laudos clínicos ou sobre doenças crônicas, está diretamente relacionado a vida diária do idoso.

Freitas (2004) afirma que o envelhecimento da população dos países em desenvolvimento acontece principalmente com os avanços na medicina, mesmo que a maioria deles apresentem algumas dificuldades, como enxergar, ouvir, se locomover, executar atividades diárias. Assim o prolongamento da vida nesses casos pode se tornar sofrida e exigir muitos cuidados. Segundo Camarano (2004), mesmo diante da realidade que os idosos brasileiros vivem, podemos encontrar indivíduos na terceira idade que apresentam disposição, saúde, inseridos no mercado de trabalho e com papéis importantes na relação familiar.

Mafra (2011), relata que o objetivo mundial para o estudo do envelhecimento é preparar o sujeito para o processo de envelhecimento, para que este tenha saúde, tanto no âmbito cognitivo, psicológico, quanto físico, como também tenha condições econômicas que possibilite ter qualidade de vida. A forma como se dá a estrutura familiar também é de suma importância, já que oferecerá apoio emocional e acolhimento a este idoso. Nesse processo de envelhecimento a OMS adotou o termo "envelhecimento ativo" que está nas conquistas da experiência positiva do envelhecer. O termo significa um processo de condições mais favoráveis de saúde, participação e segurança, objetivando dar melhor qualidade de vida a partir do envelhecimento. 
À medida que as pessoas envelhecem, as doenças não transmissíveis são as maiores causadoras de morbilidade, incapacidade e mortalidade em todas as regiões do mundo. As principais doenças crônicas que afetam os idosos são: doenças cardiovasculares, hipertensão, derrame, diabetes, câncer, doenças mentais, doenças pulmonares, doenças músculoesqueletica, cegueira e demências (OSM,2012). É importante chamar a atenção dos riscos dessas doenças desde jovem, cuidando da alimentação, praticando exercícios físicos, excluindo o tabagismo, alcool e outros fatores de risco.

É importante lembrar que a perda da memória causada pela doença de Alzheimer é diferente da perda da memória causada pelo processo de envelhecimento, a primeira é devastadora e progressiva e a segunda, benigna e de desenvolvimento mais lento ( Kandel, 2009)

\section{A Mulher e o Alzheimer}

Rocha e Bartholo (2010), afirmam que os mais diversos tipos de transtornos mentais comuns têm seu aumento a partir do envelhecimento e se processa com mais frequência nas mulheres principalmente as sedentárias, fumantes e solitárias. Nota-se que algumas perdas cognitivas, como também os transtornos de ansiedade e a depressão são os problemas de saúde que mais acometem a população idosa (IRIGARAY e SCHNEIDER, 2007). A sensação de não pertencimento, dificuldade de planejar o futuro, dificuldade de adaptação com as mudanças, desmotivação, perda do contato social, baixa autoestima e autoimagem, medo, ansiedade e insegurança são limitações psicológicas relevantes no processo de envelhecimento que podem ser fatores do desenvolvimento de depressão maior. Fazer com que esse momento da vida seja levado de forma saudável é um desafio para todas as pessoas envolvidas no processo, como os familiares e os especialistas da área de saúde.

A Doença de Alzheimer por sua vez é uma forma de demência, que acomete cerca de 5\% dos indivíduos com mais de 65 anos e $20 \%$ das pessoas com mais de 80 anos.(INOUYE, PEDRAZZANI e PAVARINI, 2010). Portanto a doença de Alzheimer é uma demência de alta prevalência na terceira idade, que segundo o Manual de Diagnósticos e Estatísticos de Transtornos Mentais (DSM-V-TR) é uma demência senil, com diminuição da capacidade cognitiva, irreversível, com déficits de memória, que gera graves prejuízos nas atividades 
diárias. Inicialmente ocorre o esquecimento de acontecimentos recentes, com a evolução da doença a paciente começa a apresentar incapacidade de executar suas atividades rotineiras, como exemplo, executar atividades domésticas, se vestir, cuidar da higiene pessoal e se alimentar, o que causa sofrimento físico e mental. Esse sofrimento é potencializado quando acontece dificuldade de linguagem, fase esta que o sujeito passa a ficar dependente de um cuidador, já que perde sua autonomia e habilidades pessoais.

Falcão (2006) destaca que é de suma importância que haja entendimento das condições de saúde do portador, endendendo o adoecimento e as possibilidades para a qualidade vida da mulher idosa com demência. É necessário ainda compreender que apesar de todas as alterações causadas pela demência, a mulher portadora da doença de Alzheimer está viva, mesmo apresentando comportamentos infantis, perdendo um pouco da sua identidade, fazendo referências a pessoas mortas como se ainda estivessem vivas ou ainda confundindoas com membros vivos. Com todas essas mudanças, profissionais e familiares têm a tendência de tratar as portadoras de DA como crianças, esquecendo que elas possuem sentimentos e não podem ser um amálgama com a doença. É de grande relevância que elas sejam escutadas, respeitadas, que sejam tradadas com respeito e amor.

Além da perda de memória grave, a paciente pode também ter outros sintomas como a incapacidade de realizar movimentos especializados, a dificuldades de reconhecer as coisas visualmente, dificuldades na linguagem, alterações do humor e outros sintomas. Muitos pacientes apresentam depressão e outros desenvolvem algum tipo de paranóia, além da agressividade que muitas vezes aparece em alguns momentos (IAN, 2002). A mulher ao chegar à terceira idade sofre mudanças físicas e emocionais. As alterações físicas principais estão relacionadas principalmente com a imagem, como cabelos grisalhos, flacidez muscular, dores ósseas, enrijecimento das articulações. As mudanças emocionais exacerbam com a aposentadoria, solidão e a sensação de impotencia, quando ocorre afastamento não só do trabalho como também dos colegas e da vida social. Todas essas alterações perturbam os registros de toda uma vida de experiências e aprendizado, acentuando o dano na pessoa, constituindo um golpe gradual no processo de devastação incapacitante.

\section{A Familia e o Alzheimer}


Os efeitos do quadro de distração e esquecimento são danosos para o próprio idoso e para seus familiares, refletindo nos aspectos da sua rotina, nas atividades da vida diária e da sua segurança. Outra atitude preocupante são as acusações e censuras extremas, sendo quase sempre causadoras de mal entendidos e de conflitos infundados. (BRUGGER, 2004). Percebe-se que a compreensão da família, cuidadores e profissionais é essencial para o acolhimento do portador de DA.

Segundo Ian (2002), com a evolução da doença, os sintomas tornam-se mais graves; a perda da memória recente, a dificiculdade de reconhecimento, a linguagem piora, dificuldades de falar e de comprender a fala, a aparência externa do paciente declina paulatinamente.

A doença de Alzheimer traz muitas demandas ao cuidador, tornando-se uma tarefa difícil de executar, uma vez que a paciente acometida por tal demência necessita de cuidados constantes, já que o cuidador é quem vai possibilitar a essa mulher a execução de certas atividades, que vão desde a higiêne à administração financeira. Toda essa mudança e esses encargos geram para o cuidador ansiedade, podendo trazer quadros depressivos diante da situação, nesse processo de readaptação a nova realidade, de quuem cuida e de quem é cuidado. Vale ressaltar que diante de tamanho cuidado e dedicação, essa mulher não tem condições de retribuir ao seu cuidador tamanha presteza. (NOVELLI, 2003)

No ano de 2002 uma decisão do Ministério da Saúde permitiu o fornecimento de medicação através da rede pública de saúde para pacientes portadores da dença de Alzheimer, o que possibilitou uma diminuição de demandas aos familiares e cuidadores, dimunuindo as despesas com o tratamento do paciente.Criou-se Centros de Referências para atendimento especializado a pessoas com doença de Alzheimer, o que possibilita ao cuidador receber apoio, mas nem todas as cidades do país dispoe desse atendimento; de fato faz-se necessário criar políticas públicas de atenção ao idoso, para que haja de fato atendimento à paciente e apoio ao familiares.(LUZARDO e WALDMAN, 2004). ( acho que nao é importante

Segundo o relato de Caldeira e Ribeiro (2004), a questão emocional da família da paciente passa por grande sofrimento e alterações no modo de vida, para poder oferecer atenção a esta mulher. Uma vez que a família se percebe diante de uma situação de sofrimento e de drásticas mudanças, difíceis de serem aceitas, já que essa portadora perde sua identidade diante do acometimento da demência, por isso o papelo do cuidador é complexo e necessário.

Silva e Neri (2000) afirmam os cuidados a essa mulher constituídas por filhos, por outros familiares e por amigos é o mais importante meio de atenção a paciente. A qualidade 
de vida e o afeto que esse cuidador vai oferecer faz toda a diferença, possibilitando até melhoria no quadro da demência. Ainda segundo Caldeira e Ribeiro (2004), a doença de Alzheimer deixa a família vítima da doença, já que muda completamente a rotina destes, o cuidador se depara com o stresse cada vez maior como administrar conflitos internos e até mesmo de como se pensar no futuro, o que pode acarretar ao cuidador inúmeras doenças, como stresse, perca de peso, doenças física, alcoolismo e uso de medicaçoes; ou seja, a sobrecarga para o cuidador é muito grande que muitas vezes não recebe apoio do restante da família.

\section{O Luto e a perda da identidade}

O processo de envelhecimento é algo inevitável para o ser humano, faz parte do ciclo de vida. A velhice é considerada a última fase antes da morte, é o periodo com maior predisposição a doenças crônica-degenerativas e as comorbidades, o que geram alterações e sofrimento para o paciente e para seus familiares.(SENA, 2006).

Demência de Alzheimer causa limitações das capacidades funcionais e consequentemente a perda de identidade do paciente, com a evolução da doença, gerando entre familiares e cuidadores uma situação dolorosa e de sofrimento, por lidar diretamente com a doença incapacitante e a finitude da vida (SENA,2006). No livro Freud e a cultura, Fuks (2007), relata que através do reconhecimento da morte de um outro que o indivíduo irá perceber a sua própria finitude, nesse sentido o cuidador percebe a realidade da paciente, mas também percebe o caminho que ele mesmo um dia chegará. Os filhos tendem a não aceitação da finitude posta com o envelhecimento e a doença, marcado pelas limitações físicas, cognitivas, perda de autonomia, identidade e independência; isso porque segundo Salvarezza (2005), os filhos se negam a aceitar o processo de envelhecimento dos pais e o seu adoecimento pois isso lhe trazem um sentimento de desamparo e fraqueza, já que foram os seus progenitores que asseguraram desde o seu nascimento a sua sobrevivência.

$\mathrm{Na}$ doença de Alzheimer, o comprometimento da cognição e as limitações trazidas pela demência ocasiona a perda da autonomia e da capacidade de decisão, segundo relata Flashman (2002). As características que a demência de Alzheimer traz à paciente são vários, abundantes e que causam grandes prejuízos na vida da portadora e de seus familiares; apesar 
das informações acessíveis sobre a doença, esse é um tipo de adoecimento que causa profundo sofrimento e angústia à família e à paciente, já que com a descoberta da doença vem também a diminuição das capacidades cognitivas, medo do estigma, a perda da dignidade pessoal e a perda de identidade com a evolução da doença (LIMA, 2006).

Freud traz no seu texto Luto e Melancolia, que "o luto, é a reação à perda de um ente querido, à perda de alguma abstração que ocupou o lugar de um ente querido, como o país, a liberdade ou o ideal de alguém, e assim por diante" (1915/2006, p.249). Diante do luto, da realidade da perda e da separação do objeto que deixou de existir; ocorre o esvaziamento das energias do ego como consequência do processo. Concentino e Viana (2011), falam da marcante associação simbólica do envelhecimento com a morte para o homem; simbolicamente a morte é vivida através das perdas durante o processo de envelhecer, o luto vem como consequência das perdas no envelhecimento, uma vez que a morte é tida como um fenômeno que causa impotência para a natureza humana. A grandiosidade da natureza humana o prende as limitações humanas onde o homem se esquiva diante da realidade da civilização. Tanto a velhice como a morte apresenta aparência de algo distante, assim tem cunho abstrato, mas que chegará e nesse momento causará profundo sofrimento. E embora não seja esperada e cause espanto no indivíduo, a morte na velhice é entendida pela sociedade como algo natural. Ainda segundo Freud, o luto está ligado a perda do objeto de investimento libidinal que foi desligado ou que não há mais investimento, que perde o objeto, algo que ele considera natural. (CONCENTINO e VIANA, 2011).

Diante disso, é notória que a doença de Alzheimer, por ser uma doença degenerativa ocasiona graves alterações na vida da mulher idosa, portadora de demência, lhe traz a perda de identidade e a certeza de mudanças, o que inicialmente traz angustia e medo, assim como deixa de ser ela mesma, como um dia foi.

\section{Considerações Finais}

Quanto mais envelhecemos, maiores são as chances do desenvolvimento das doenças degenerativas e incapacitantes, muito embora essas doenças também possam acometer pessoas na idade adulta e até mesmo, na juventude. Inúmeros estudos têm buscado encontrar soluções para esse enigma da esfinge cerebral. O cérebro humano guarda as informações por 
muito tempo e depois, sem motivo aparente o que foi guardado começa a se perder no emaranhado de neurônios e suas sinapses. E a mente, com suas inquietações e angustias, pode cair no precipício da depressão, acelerando ou iniciando o quadro demencial do idoso. Déficit de memória é comumente associado com depressão em pacientes idosos e pode, muitas vezes, ser inicialmente o único sintoma presente.

A doença de Alzheimer é uma demência cerebral primária, que tem relação com o sexo e a idade; sabendo-se que há maior prevalência entre mulheres idosas e mais velhas. A demência se instala de forma silenciosa e lenta, inicialmente começa com quadro de perda de memória, com a sua evolução traz maiores prejuízos e alterações, como défict da função cognitiva, diminuição das atividades motoras, mudanças de humor, dificuldade de linguagem, perda de peso, esquecimento das palavras, dificuldade de falar, o não reconhecimento das pessoas de seu convívio, dentre outros.

Com todas as alterações trazidas pela doença de Alzheimer, essa mulher da terceira idade, portadora de tal demência, sofre várias alterações na sua vida, nas suas atividades, o que lhe causa medo, angustia e dependência pelo cuidador. Essas mudanças são percebidas por essa paciente ainda na fase inicial,com a evolução da doença a família percebe a perda de identidade essa mulher, entende também a finitude da vida e tudo isso ocasiona sofrimento aos familiares.

Apesar de não haver descoberto ainda a causa e a cura de tal doença, existem dois medicamentos que evita a evolução da demência.E dentro do contexto da evolução da doença, essa mulher precisa de qualidade de vida, afeto e cuidados, pelo menos um membro da família geralmente se dispõe a ser o cuidador; a família procura oferecer qualidade de vida para esta paciente. Nesse processo tão doloroso, faz-se necessário a criação de políticas públicas qu auxiliem o cuidador, assim como também ofereça atendimento ao paciente, aonde existe programas nesse sentido ainda não funcionam de forma eficaz.

A mulher enfrenta o envelhecimento com grandes dificuldades, até porque inseridas em uma sociedade capitalista, onde muito se é cobrado pela aperência perfeita, à percepção do corpo que se transforma causa sofrimento a mulher; mais ainda sofre essa paciente acometida pela doença de Alzheimer que sofre maiores maiores prejuízos e alterações, perdendo então sua identidade, modificando a sua rotina e alterando a estrutura familiar. Nesse contexto essa mulher necessita de atenção e cuidados para que possa enfrentar esses adoecimento. 
Percebe-se diante da construção desse artigo, que sendo uma revisão bibliográfica, encontramos precariedade na literatura científica no que se refere ao estudo da perda de identidade da mulher acometida pela doença de Alzheimer, assim como uma melhor compreensão do prejuízos causados pelo adoecimento de tal demência são pouco encontrados na literatura científica. As limitações e alterações que a Doença de Alzheimer traz à sua portadora, são de maior prevalência na literatura científica. Observa-se então que este não foi uma trabalho fácil, exigi-se grande dedicação, por haver escacez na literatura científica no que se propunha os objetivos, não se alcançou completamente os objetivos como foi idealizados inicialmente. A pesquisa não se pretende esgotar o tema, mas realizar uma reflexão sobre a necessidade de outros estudos, assim é possível que sirva para contribuir na compreensão da Doença de Alzheimer,e outros trabalhos poderão complementar o estudos sobre este tema.

\section{Referências}

AMBAN - PROGRAMA ANSIEDADE [Internet]. 1. Transtornos de ansiedade; 2. Manifestações Clínicas. [acesso em 20 de novembro de 2017]. Disponível em: http://www.amban.org.br/content/textos-educativos.

AMADO L; BERVIAN, PEDRO A. Pesquisa - conceitos e definições. In: Metodologia cientifica. São Paulo: Prentice Hall, $5^{\text {a }}$ Ed. 2003.

ANDRADE, B. A; et al. Promoção da saúde metal do idoso na atenção básica: as contribuições da terapia comunitária. 2010. Disponível em: 〈http://www.scielo.br/pdf/tce/v19n1/v19n1a15>. Acesso em 09 de Abril 2016.

ARAUJO, C. et al. Métodos de Investigação em Educação Docente: estudo de caso. 2008. Mestrado em Educação Área de Especialização em Tecnologia Educativa Unidade Curricular. Disponível em: <http://grupo4te.com.sapo.pt/estudo_caso.pdf >. Acesso em: 18 maio 2016.

BARRETO, M.da S., CARREIRA, L., e MARCON, S.S. (2015, janeiro-março). Envelhecimento populacional e doenças crônicas: Reflexões sobre os desafios para o Sistema de Saúde Pública. Revista Kairós Gerontologia, 18(1), pp. 325-339. ISSN 1516-2567. ISSNe 2176-901X. São Paulo (SP), Brasil: FACHS/NEPE/PEPGG/PUC-SP

BIBLIOTECA Prof, Paulo de Carvalho Matos. 2005. Disponível em: $<$ http://www.fca.unesp.br/Home/Biblioteca/tipos-de-evisao-de-literatura.pdf $>$. Acesso em $12 \mathrm{de}$ novembro de 2016.

CID 10. Disponível em: <https://books.google.com.br/books?hl=pt$\mathrm{BR} \& \mathrm{lr}=\& \mathrm{id}=\mathrm{PQhs} 3 \mathrm{R} x 4 \mathrm{~b} 8 \mathrm{C} \& \mathrm{oi}=\mathrm{fnd} \& \mathrm{pg}=\mathrm{PA} 1 \& \mathrm{dq}=\mathrm{cid}+10 \& \mathrm{ots}=\mathrm{nl}$ DmOlQpl\&sig=3wLBXLxwngf npd-7dd-577oXdHU\#v=onepage $\& \mathrm{q}=\mathrm{cid} \% 2010 \& \mathrm{f}=$ false $>$. 
CONCENTINO, J.M. B, e VIANA, T.C. A Velhice e a morte: reflexões sobre o processo de luto. Disponível em:

< http://www.scielo.br/pdf/rbgg/v14n3/v14n3a18 >. Acessado em: 10 de novembro de 2016

FUENTES, Daniel, DINIZ, Leandro, Malloy, CAMARGO, Candida,Pires. Neuropsicologia: teoria e prática. Porto Alegre: Artmed

LITVOC, Júlio e BRITO, Francisco Carlos. Envelhecimento: prevenção e promoção de saúde. São Paulo: Editora Atheneu,2004.

IAN, Hamilton Stuart. A psicologiado Envelhecimento : uma introdução. Porto Alegre: Artmed, 2002.

NERI, Anita Liberalesso. Qualidade de vida na velhice. Campinas, SP: Editora Alíneas,2011.

BAUMAN, Zygmunt. Amor líquido: sobre a fragilidade dos laços humanos. Rio de Janeiro: Jorge Zahar; Ed., 2004.

BEAUVOIR, S. Tradução de Maria Helena Franco Monteiro. Rio de Janeiro: Nova Fronteira,1990.

BORN.T. Cuidado ao idoso em instituição. In: NETTO, M. P. (Org) Gereontologia: A velhice e o envelhecimento em visão globalizada. São Paulo: Atheneu. 1996.

BRAMANTE, A. C. Qualidade de vida e lazer. Em Gonçalves, A. \& Vilarta (Org). Qualidade de vida e atividade física: explorando teorias e práticas. Barueri, SP: Manole, 2004.

BRASIL, Senado Federal- Secretaria Especial de Editoração E. Estatuto do Idoso. 2000. Disponível em: www.livrosgratis.com.br/arquivoslivros/sf00012a.pdf>. Acesso em 10 de abril de 2016.

BRUGGER. F. M. M. Psicomotricidade de saúde mental na terceira idade. 2004. Disponível em: <http://www.avm.edu.br/monopdf/7/FRANCILEUDA\%20MELO\%20MOREIRA\%20BRUGGER. pdf. Acesso em 18 de abril 2016.

CALDEIRA, A, P.S e RIBEIRO, R, C, H, M. O enfrentamento do cuidador de idoso com Alzheimer. 2004. Disponível em:< http://repositorio-racs.famerp.br/racs_ol/Vol-11-2/ac08\%20\%20id\%2027.pdf>.Acessado em 09 de novembro de 2016.

CÂNDIDO. G.V; COSENTINO. M.C; DARAHEM. G. C. O uso da história oral na Psicologia: percepção de experiências individuais. Disponível em: <http://www.epublicacoes.uerj.br/index.php/revispsi/article/view/13900/10616>. Acesso em 10 de abril de 2016.

CAMARANO, A. A; KANSO. S. As instituições de longa permanência para idosos no Brasil. 2010. Disponível em: < http://www.scielo.br/pdf/rbepop/v27n1/14.pdf>. Acesso em 10 de abril de 2016.

CAPITANINI, M. E. S \& NERI, A. L. Sentimentos de solidão, bem-estar subjetivo e relações sociais em mulheres idosas vivendo sozinhas. Em Neri, A. L. \& Yassuda, M. S. (Org.) Velhice bem sucedida: Aspectos afetivos e cognitivos. Campinas, SP: Papirus, 2004. 
CHRISTOPHE. M. Instituições de Longa Permanência para Idosos no Brasil: uma opção de cuidados de longa duração? $2007 . \quad$ Disponível em:〈http://www.faceconsultoria.com.br/uploads/pdf/20531fe06e6e0e9a65351c240c8aa428.pdf>.

Acesso em: 20 de abril 2016.

CORREA. M. R; JUSTO. J. S. Oficinas de psicologia: memória e experiência narrativa com idosos. 2010. Disponível em: < http://www.uel.br/revistas/uel/index.php/eip/article/view/8666/7263>. Acesso em: 15 de maio 2016.

BRASIL. Estatuto do Idoso. Lei ${ }^{\circ} 10.741$, de $1^{\text {a }}$ de outubro de 2003. Brasília: Secretaria Especial dos Direitos Humanos, 2004, 44p. Brasília, 2008

BORN.T. Cuidar Melhor e Evitar a Violência Manual do Cuidador da Pessoa Idosa. 2008. . Disponível em:< http://www.sdh.gov.br/assuntos/pessoa idosa/legislacao/pdf/manual-do-cuidadorada-pessoa-idosa>. Acesso em: 20 de abr. 2016.

DARAHEM.G.C et al. O uso da história oral na Psicologia: percepção de experiências individuais. 2014. Disponível em:< http://pepsic.bvsalud.org/pdf/epp/v14n3/v14n3a19.pdf >. Acesso em: 20 de abr. 2016.

ERIKSON, E. H - Teoria do desenvolvimento psicossocial, 7 ed. 2010. Disponível em:<http://www.carpsi.com.br/Newsletter_7_ago-10.pdf>. Acesso em: 20 de abr. 2016.

FALCÃO,D.V.S - Doença de Alzheimer: um estudo sobre o papel das filhas cuidadoras e suas relações familiares.2006. Disponível em: $<$ http://repositorio.unb.br/bitstream/10482/3742/5/capitulo5_6.pdf $>$.Acesso em: 08 de novembro de 2016.

FRAGOSO, V. Humanização dos cuidados a prestar ao idoso institucionalizado. RevistaI IGT na rede.Vol.5, $\mathrm{n} \quad$ 8,p. 51-61, 2008. <http://www.igt.psc.br/ojs/viewarticle.php?id=178layout=html>. Acessado: 15 maio 2016.

FILHO, L. F. B. O processo de envelhecimento e o comportamento vocal. Rio de Janeiro: 1999.

FREIRE, S. A. Educação permanente e qualidade de vida na velhice: meta e desafio na atualidade. Em 3 congresso Paulista de Geriatria e Gerontologia. Santos: SBGG. São Paulo. Santos, 2003.

FREITAS. M. C; QUEIROZ. A. T; SOUSA. J. A. V. O significado da velhice e da experiência de envelhecer para os idosos. 2009. Disponível em:<http://www.scielo.br/pdf/reeusp/v44n2/24.pdf >. Acesso em: 20 de abril 2016.

FORTES-BURGOS, A.C.G.; NERI, A. L.; CUPERTINO, A.P.F.B. Eventos de vida estressantes entre idosos brasileiros residentes na comunidade. Estudo Psicol. 2009, 14 (1): 69-75. Disponível em: <www.scielo.br/pdf/epsic/v14n1/a09v14n1.pdf>. Acesso em: 20 de abril 2016.

FORTES, A. C. G \& NERI, A. L. Eventos de vida e envelhecimento humano. In: Neri, A. L.; YASSUDA, M. S. (Org.) Velhice bem sucedida: Aspectos afetivos e cognitivos. Campinas, SP: Papirus, 2004.

FROTA NAF, NITRINI R, DAMASCENO BP, Forlenza O, Dias-Tosta E, da Silva AB, et al. Critérios para o diagnóstico de doença de Alzheimer. Dement Neuropsychol 2011; 5 Suppl 1:5-10.

FUKS.B.B. Freud e a cultura.Editora Zahar. $1^{\circ}$ Ed. 2007. 
GERRIG, R. J; PHILIP G. Z. A psicologia e a vida. Trad. Roberto Cataldo Costa. 16 ed.- Porto Alegre: Artmed, 2005.

GODOY.A.S. Pesquisa qualitativa, tipos fundamentais. Revista de administração de empresa, São Paulo, p.20-29,1995. Disponível em: < http://www.scielo.br/pdf/rae/v35n3/a04v35n3>. Acesso em: 22 de fevereiro 2016.

GOFFMAN, E. Goffman: Contribuições para a Sociologia da Saúde. Vol. 10. Rio de Janeiro. 2009. Disponível: <http://www.scielo.br/scielo.php?script=sci_arttext\&pid=S0103-73312009000100009 >. Acesso em 19 de abril 2016.

GONÇALVES, A. E VILARTA,R. Qualidade de vida e atividade física: explorando teoria e prática. Ed. Manole, 1 ed, São Paulo, 2004

INOUYE, K. E PEDRAZZANI, E. S. E PAVARINI, S. C.Influência da doença de Alzheimer na percepção de qualidade de vida do idoso. Disponível em: $<$ http://reposip.unicamp.br/bitstream/REPOSIP/1695/1/art PEDRAZZANI Influencia da doenca _de_Alzheimer_na_percepcao_2010.pdf > Acessado em 08 de novembro de 2016.

INSTITUTO DE PESQUISA ECONÔMICA APLICADA. PNAD-2007 primeiras análises: demografia e gênero. Rio de Janeiro: Instituto de Pesquisa Econômica Aplicada; 2008. (Comunicados da Presidência, 11).

IRIGARAY. T. Q; SCHNEIDER. R. H. Prevalência de depressão em idosas participantes da universidade para a terceira idade. Revista Psiquiatra RS. 2007. Disponível em: < http://www.scielo.br/scielo.php?script=sci_arttext\&pid=S0101-81082007000100008 >. Acessado em 08 de abril2016.

LUZARDO,A.R., GORIM,M.I.P.C.,SILVA,A.P.S.S. Características de idosos com doença de Alzheimer e seus cuidadores: uma série de casos em um serviço de neurogeriatria. Disponível em: 〈http://www.scielo.br/pdf/tce/v15n4/v15n4a06 > . Acessado em: 08 de novembro de 2016.

LUZARDO,A.R. E WALDMAN,B.F. Atenção ao familiar cuidador do idoso com doença de Alzheimer. Disponível em: <http://www.lume.ufrgs.br/bitstream/handle/10183/140057/000590924.pdf?sequence=1>.Acessado em: 08 de novembro de 2016

MAFRA, Simone Caldas Tavares. A tarefa do cuidar e as expectativas sociais diante de um envelhecimento demográfico: a importância de ressignificar o papel da família. 2011. Disponível em: <http://www.scielo.br/pdf/rbgg/v14n2/v14n2a15 $>$. Acessado em 02 de Novembro de 2016.

MARIM. M.J.S et al. Compreendendo a História de Vida de idosos institucionalizados. 2012. Disponível em: <http://www.scielo.br/pdf/rbgg/v15n1/16.pdf>. Acesso em: 11 de maio 2016.

MORAES EN. Incapacidade cognitiva: abordagem diagnóstica e terapêutica das demências no idoso. 2.ed. Belo Horizonte: Folium; 2010.

NERI, A. L. As múltiplas faces da velhice no Brasil. Campinas, SP: Papirus, 2003.

NERI, A. L. Qualidade de vida na velhice. Enfoque multidisciplinar. $2^{\text {a }}$ Ed. Campinas, SP: Editora Alínea, 2008 
NERI, A. L. O que a Psicologia tem a oferecer ao estudo e à intervenção no campo do envelhecimento no Brasil, hoje. In: Neri, A. L.; YASSUDA, M. S. (Org.). Velhice bem-sucedida: Aspectos afetivos e cognitivos. Campinas, SP: Papirus, 2004.

NERI, A. L.; SOMMERHALDER. C. As várias faces do cuidado e do bem-estar do cuidador In: Neri, A. L. (Org.) Cuidar de idosos no contexto da família: questões psicológicas e sociais. Campinas, SP: Ed Alínea, 2002.

NOVELLI,M. M.P.C. Adaptação transcultural da escala de avaliação de qualidade de vida na doença de Alzheimer. 2003.2 Disponível em: <www.teses.usp.br/teses/.../5/../MarciaMariaPiresCamargoNovelli>. Acessado em 12 de novembro de 2016.

OLIVEIRA. S.A. A Importância das Relações Sócio-Familiares na Promoção da Qualidade de Vida do Idoso. 2009.20 Disponível em: <http://repositorio.uniceub.br/bitstream/123456789/2899/2/20163105.pdf>. Acesso em 10 de maio 2016.

ORGANIZAÇÃO MUNDIAL DA SAÚDE (OMS). Relatório mundial da saúde. Saúde mental: nova concepção, nova esperança. Lisboa, 2001.

PAPILA,D,E e FELDMAN, R.D. Desenvolvimento Humano. Editora Artmed. $8^{\circ}$ Ed.Rio Grande do Sul:2006.

PASCHOAL, S. M. C. Avaliação da qualidade de vida. Mesa redonda apresentada no XIV Congresso Nacional de Geriatria e Gerontologia. Salvador, Bahia: 2004.

PAVARINI, SCI. Dependência comportamental na velhice: uma análise do cuidado prestado ao idoso institucionalizado [Tese]. Campinas: Universidade Estadual de Campinas; 1996.

PARK, M. B. O ciclo da vida representado nas páginas dos almanaques de farmácia brasileira. In: Simson, O. R. M. V., \& NERi, A. L.; CACHIONI, M., (2003). (Org.). As múltiplas faces da velhice no Brasil. Campinas, SP: Papirus, 2003.

PESKIND, Elaine R., RASKIND, Murray A. Transtornos cognitivos. In: BUSSE,Ewald W., BLAZER, Dan G. Psiquiatria geriátrica. Tradução Maria Rita Secco Hofmeister e Dayse Batista. 2 ed. Porto Alegre: Artmed, 1999. p. 223-243. Memória e envelhecimento: aspectos neuropsicológicos e estratégias preventivas. 2006. Disponível em:

<http://www.psicologia.pt/artigos/textos/A0302.pdf > Acesso em 02 de Novembro de 2016

RAMOS,L.R. Fatores determinantes do envelhecimento saudável em idosos residentes em centro urbano: Projeto Epidoso, São Paulo. Cad. Saúde Pública [online]. 2003, vol.19, n.3, pp.793797.Disponível

em: $<$ http://www.scielosp.org/scielo.php?pid=S0102311X2003000300011\&script=sci_abstract\&tlng=e nen>. Acessado em 15 de agosto de 2015.

RODRIGUEZ, j. L. \& HERRERA, R. F. G. Demencias y enfermedad de Alzheimer en América Latina y el Caribe. Revista Cubana de Salut Pública. V.40, n.3, p.378-387, 2014

ROCHA. F. N; BARTHOLO. M. C. Educação e Qualidade de Vida de Idosos: Uma Reflexão Necessária, 2010.

Disponível

$\mathrm{em}:<$ http://www.uss.br/pages/revistas/revistamosaico/V1N22010/pdf/03\%20Educacao\%20e\%20Qualidade $\% 20$ de\%20vida.pdf $>$. Acesso em: 10 de maio 2016. 
ROCHA, S.V.; ALMEIDA, M.M.G. de. ARAUJO, T.M. de. VIRTUOSO JUNIOR, J.S. Prevalência de transtornos mentais comuns entre residentes em áreas urbanas de Feira de Santana, Bahia. Rev. Bras. Epidemiol. 2010: 13(4).

SADOCK.J e SADOCK. A. Psychiatry: Behavioral Sciences/Clinical Psychiatry. Disponível em: <https://books.google.com.br/books?id=fFi7DR2hmaIC\&pg=PR6\&dq=SADOCK+J.+e+SADOCK+A $.+2007 \& \mathrm{hl}=$ pt-BR\&sa=X\&ved=0ahUKEwic-q_Lv6TQAhVDTZAKHSDxB7IQuwUIIzAA\# $\mathrm{v}=$ onepage $\& \mathrm{q}=\mathrm{SADOCK} \% 20 \mathrm{~J} . \% 20 \mathrm{e} \% 20 \mathrm{SADOCK} \% 20 \mathrm{~A} . \% 202007 \& \mathrm{f}=$ false $>$. Acessado em $20 \mathrm{de}$ agosto de 2015.

SALVAREZZA L. Fausto MSV. A propósito de La construcción del imaginário social sobre La vejez. In: Salvarezza L. La vejez: uma mirada gerontológica actual. Buenos Aires: Paidós;2005.

SEIDL, E.M.F.; ZANNON, G.M.L.C. Qualidade de Vida e Saúde: aspectos teóricos e metodológicos. Cadernos de Saúde Pública. V. 20, n.2, p. 580-588, mar-abr/2004.

SENA, E,L.S,. A experiência do outro nas relações de cuidado: uma visão Merleau-Pontyana sobre as vivências de familiares cuidadores de pessoas com Doença de Alzheimer. 2006. Disponível em: <https://repositorio.ufsc.br/handle/123456789/88759>. Acessado em 07 de novembro de 2015.

SILVA, M. A. D. e MARCHI, R. Saúde e qualidade de vida no trabalho. São Paulo: Best Weller, 1997.

SILVA, E. B. do N.; NERI, A. L. Questões geradas pela convivência com idosos: indicações para programas de suporte familiar. In: NERI, A. L. (Org.). Qualidade de vida e idade madura. 3. Ed. São Paulo: Papirus, 2000. P. 213-236.

SILVA, M.J.; VARELA, Z. M. O conceito de adaptação na terceira idade: uma aproximação teórica. Arquivos de Geriatria e Gerontologia, 3 (1), p. 25-29, 1999.

SILVA.V. Velhice e envelhecimento: qualidade de vida para os idosos inseridos nos projetos do sescestreito. 2009. Disponível em:< http://tcc.bu.ufsc.br/Ssocial287076.pdf.2009>. Acesso em 20 de abril 2016.

TEIXEIRA. F. O idoso e a família: os dois lados da mesma moeda. 2000. Disponível em:< http://www.partes.com.br/terceira_idade08.html>. Acessado em: 21 de abril 2016.

TESSER, C. D. Medicalização social (II): limites biomédicos e propostas para a clínica na atenção básica. Interface. v. 10, n. 20, p. 347-362. 2006. Disponível em:http://www.scielo.br/scielo.php?script=sci_arttext\&pid=S1414-

32832006000200006\&lng=en\&nrm=iso\&tlng=pt. Acesso em: 25 de abril 2016.

TINOCO, R. Histórias de vida: Um método qualitativa de investigação. 2004. Disponível em: <http://www.miniwebcursos.com.br/curso_aprender/modulos/aula_4/artigos/A0349.pdf>. Acesso em: 25 de abril 2016.

TETTAMANZY. A.L.L; TORRES. S.M. Contação de histórias: resgate da memória e estimulo à imaginação. Porto Alegre - Vol. 04 N. $01-$ jan/jun 2008. Disponível em: http://seer.ufrgs.br/index.php/NauLiteraria/article/view/5844/3448. Acesso em: 15 de maio 2016. 
WATANABEI. H.A.W; GIOVANNIII. V. M. Instituições de Longa Permanência para Idosos (ILPI).Bis,Bl. Insti. Saúde (Impr), n.47. São Paulo.2009. Disponível em: $<$ http://periodicos.ses.sp.bvs.br/scielo.php?script=sci_arttext\&pid=S1518$18122009000200018 \& \operatorname{lng}=$ es\&nrm=iso>. Acesso em 18/05/2016.

\section{Como citar este artigo (Formato ABNT):}

FERNANDES, Melina Raabi Santos; MELO, Maria do Socorro T.; MARANHÃO, Thércia L. G.; SAMPAIO, Fernanda Tesla P.; BATISTA, Hermes M.T. Doença de Alzheimer nas Mulheres: Prejuízos Pessoais e Luto Familiar. Id on Line Revista Multidisciplinar e de Psicologia, 2017, vol.12, n.39, p.533-551. ISSN: 1981-1179.

Recebido: 09.01.2018

Aceito: 11.01 .2018 